\section{The Royal College of Surgeons of Edinburgh re-launches the FDS by Assessment}

\author{
R. Chate ${ }^{1}$ and A. Shelley ${ }^{2}$
}

Please send any ideas for feature articles for consideration to:

Rowena Milan,

British Dental Journal,

The Macmillan Building,

4-6 Crinan Street,

London

N1 9XW

Email:r.milan@nature.com

Rob Chate and Andrew Shelley, co-leads for the Fellowship in Dental Surgery of the Royal College of Surgeons of Edinburgh by Assessment, outline the recently revised diploma and advise on the preparation that will be required for the first diet in March 2010.

In 2008, the Royal College of Surgeons of Edinburgh decided to revise and relaunch its Fellowship in Dental Surgery by Assessment. This will enable dentists in all branches of the profession, who have not followed consultant training, to still become fellows of the college and be awarded the FDS RCSEd.

The purpose of the assessment will be to recognise those who have demonstrated a sustained commitment to high clinical standards and to the profession of dentistry. Candidates will normally become eligible five years after achieving a Membership in General Dental Surgery (MGDS) or a specialty dental membership diploma from any College recognised by the Royal College of Surgeons of Edinburgh.

Other eligible specialist memberships are those in:

- Dental public health

- Oral medicine

- Oral surgery

- Orthodontics

- Paediatric dentistry

- Restorative dentistry

- Special care dentistry

- Surgical dentistry.

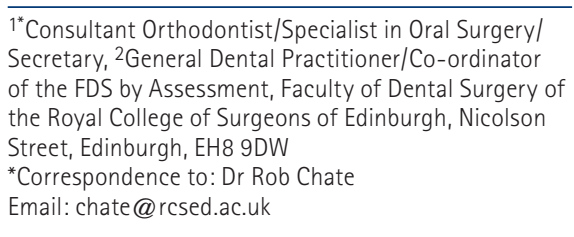

DOI: 10.1038/sj.bdj.2009.569

\section{STRUCTURE OF THE ASSESSMENT}

There are three parts to the assessment. They must all be passed independently:

1. A Fellowship portfolio

2. Two referee reports

3. A peer review.

\section{Fellowship portfolio}

Each Portfolio is comprised of the following five sections:

1. Practice of dentistry

2. Service to the profession

3. Two clinical audits

4. A documented case history or significant dental public health initiative

5. Continuing professional development (CPD).

\section{Practice of dentistry}

For this section, a description of the applicant's clinical practice and how this has developed since acquiring the MGDS or a specialty membership diploma should be given.

\section{Service to the profession}

The assessment is designed to recognise a range of different but equally valuable contributions an individual may have made to the profession. Examples would include a particular clinical expertise, service to special needs groups, teaching, examining, clinical or academic research, being an audit facilitator or an office bearer of a professional organisation.

\section{Two clinical audits}

This section will include details of two separate audits that have been completed within the preceding five years. Each audit will include at least two cycles, a summary of the findings and actions taken.

\section{A case history/dental public health initiative}

The fully documented case history should consist of a detailed and illustrated report of a patient personally treated by the candidate demonstrating a high calibre of skill in general dental practice or their specific clinical discipline. Alternatively, a significant dental public health initiative may be described.

\section{Continuing professional development}

Finally, the portfolio should contain the candidate's CPD record and a reflective commentary. The United Kingdom General Dental Council's five yearly cycle requirement for CPD will be the minimum requirement.

\section{Referee reports}

The candidate should submit reports from two referees. These will be dental surgeons who hold an MGDS or specialty dental membership diploma from a recognised College and who have known the candidate for at least five years. They should be familiar with both the candidate's clinical practice and professional activities.

\section{Peer review}

The FDS by Assessment is experience 


\section{FEATURE}

based and the peer review section is intended to reassure the examiners of the benefit gained from life-long learning. This will consist of an interview held at the College which will centre on, but not be confined to, the candidate's portfolio. Any topic of relevance may be discussed, such as clinical developments, management or wider issues involving developments within the profession.

\section{CANDIDATE PREPARATION AND APPLICATION}

The first diet for the re-launched FDS RCSEd by Assessment diploma is scheduled for 3 and 4 March 2010. This should give sufficient time for candidates to prepare and construct their portfolios prior to their submission in approximately nine months time.

Full details of the FDS by Assessment are available from the College website www.rcsed.ac.uk. Or you may contact the College at the following address:

Information Section

The Adamson Centre

The Royal College of

Surgeons of Edinburgh

3 Hill Place

Edinburgh, EH8 9DS

Tel: +44 (0)131 6689222

Fax: +44(0) 1316689218

Email: information@rcsed.ac.uk

Acknowledgements are due to professors Jonathan Cowpe, the past Dean and Elizabeth Davenport, the Convener of Examinations of the Faculty of Dental surgery of the Royal College of Surgeons of Edinburgh for their work in re-designing the FDS by Assessment diploma.

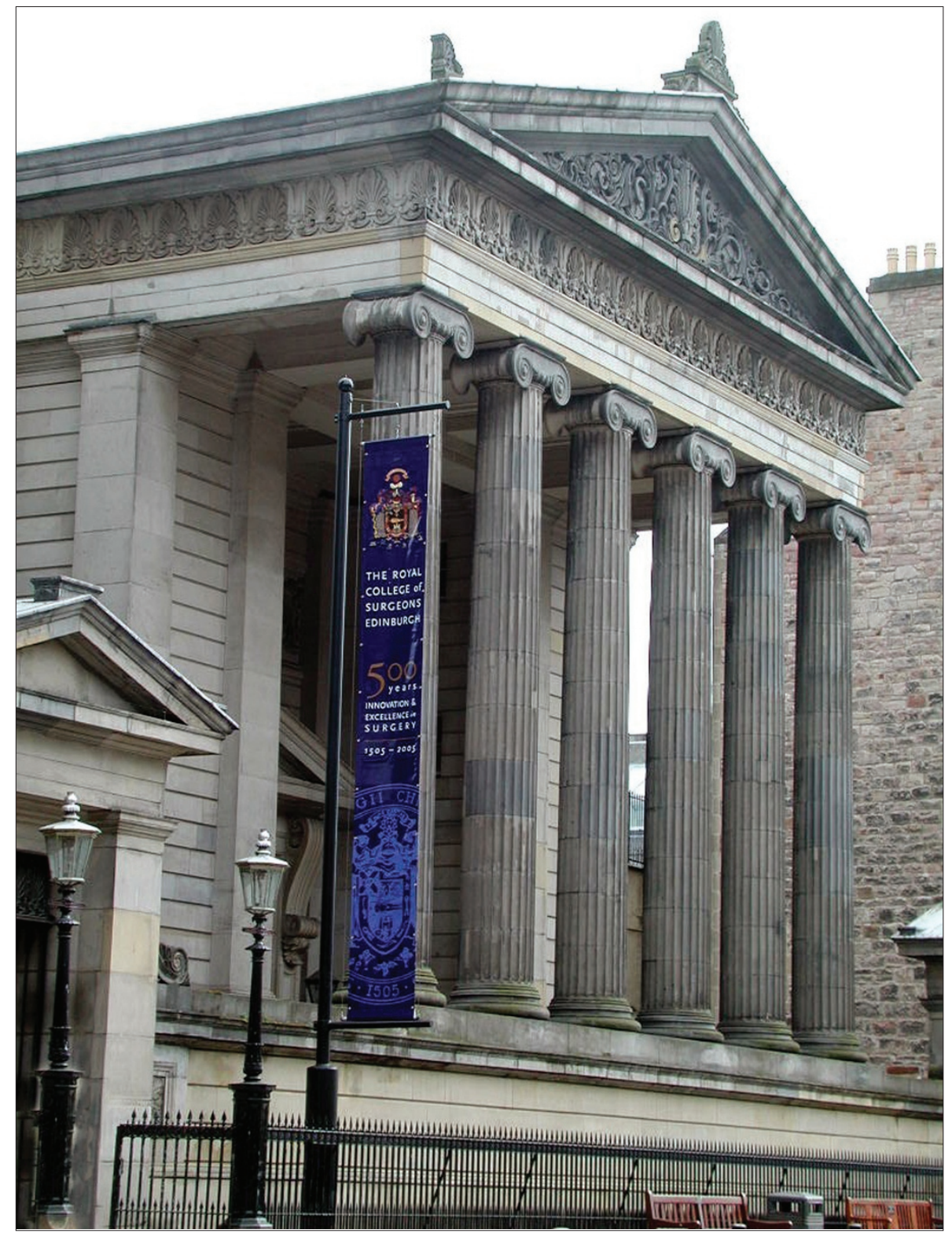

The Royal College of Surgeons of Edinburgh 